ARTICLE

DOI: $10.1038 / s 41467-018-05309-y$

\title{
Insulin/Snail1 axis ameliorates fatty liver disease by epigenetically suppressing lipogenesis
}

Yan Liu', Lin Jiang ${ }^{1}$, Chengxin Sun ${ }^{1}$, Nicole Ireland', Yatrik M. Shah ${ }^{1,2}$, Yong Liu ${ }^{3}$ \& Liangyou Rui (i) ${ }^{1,2}$

Insulin stimulates lipogenesis but insulin resistance is also associated with increased hepatic lipogenesis in obesity. However, the underlying mechanism remains poorly characterized. Here, we show a noncanonical insulin-Snail1 pathway that suppresses lipogenesis. Insulin robustly upregulates zinc-finger protein Snail1 in a PI 3-kinase-dependent manner. In obesity, the hepatic insulin-Snail1 cascade is impaired due to insulin resistance. Hepatocyte-specific deletion of Snail1 enhances insulin-stimulated lipogenesis in hepatocytes, exacerbates dietary NAFLD in mice, and attenuates NAFLD-associated insulin resistance. Liver-specific overexpression of Snail1 has the opposite effect. Mechanistically, Snail1 binds to the fatty acid synthase promoter and recruits HDAC1/2 to induce deacetylation of H3K9 and H3K27, thereby repressing fatty acid synthase promoter activity. Our data suggest that insulin pathways bifurcate into canonical (lipogenic) and noncanonical (anti-lipogenesis by Snail1) two arms. The noncanonical arm counterbalances the canonical arm through Snail1-elicited epigenetic suppression of lipogenic genes. Impairment in the insulin-Snail1 arm may contribute to NAFLD in obesity.

\footnotetext{
${ }^{1}$ Department of Molecular \& Integrative Physiology, University of Michigan Medical School, Ann Arbor, MI 48109, USA. ${ }^{2}$ Department of Internal Medicine, University of Michigan Medical School, Ann Arbor, MI 48109, USA. ${ }^{3}$ College of Life Sciences, the Institute for Advanced Studies, Wuhan University, Wuhan 430072, China. Correspondence and requests for materials should be addressed to L.R. (email: ruily@umich.edu)
} 
$\mathrm{P}$ revalence of nonalcoholic fatty liver disease (NAFLD) increases in an alarming pace due to the obesity epidemic ${ }^{1}$. The outcomes of NAFLD are ominous, including insulin resistance, type 2 diabetes, dyslipidemia, cardiovascular disease, liver fibrosis, cirrhosis, and/or hepatocellular carcinoma ${ }^{1-3}$. Liver lipid levels are determined by an interplay between de novo lipogenesis, lipid uptake, fatty acid $\beta$ oxidation, and very lowdensity lipoprotein (VLDL) secretion. Notably, hepatic lipogenesis increases in $\mathrm{NAFLD}^{4,5}$, and genetic disruption of the hepatic lipogenic program prevents NAFLD ${ }^{6-8}$. Thus, inhibiting hepatic lipogenesis likely provides a therapeutic strategy for combatting NAFLD.

Liver lipogenesis is regulated predominantly by metabolic hormone insulin. Insulin stimulates the canonical lipogenic pathway, including activation of lipogenic transcription factors liver $\mathrm{X}$ receptor (Lxr), Srebp-1c, and upstream stimulatory factor-1 (Usf-1) $)^{5,9}$. These nuclear proteins activate expression of lipogenic enzymes ATP citrate lyase (Acl), acetyl coenzyme A carboxylase 1 (Acc1), and/or fatty acid synthase (Fasn) ${ }^{5}$. Paradoxically, insulin resistance is associated with increased hepatic lipogenesis in obesity, contributing to NAFLD ${ }^{10}$. However, the underlying mechanism remains poorly understood.

We recently reported that insulin upregulates adipose Snail1 that in turn suppresses expression of adipose triacylglycerol lipase (ATGL) and ATGL-mediated lipolysis ${ }^{11}$. Snail1 is a transcriptional repressor, and has been known to induce epithelial-tomesenchymal transition (EMT) during development or in cancer metastasis $^{12-14}$. Snaill has been well documented to epigenetically suppress expression of E-cadherin and claudin, thus promoting EMT ${ }^{15-18}$. Mechanistically, Snail1 binds via its N-terminal SNAG domain to several epigenetic enzymes, including histone deacetylases (HDACs) and histone methyltransferases, and recruit them to target promoters where these enzymes catalyze repressive histone modifications ${ }^{14,15}$. Notably, we found two reports that describe the potential action of hepatic Snail1 in liver injury and regeneration ${ }^{19,20}$; however, the metabolic function of hepatic Snaill has not been explored. In this study, we provide proof of concept evidence showing that hepatic Snaill is an unrecognized suppressor of de novo lipogenesis. It epigenetically represses expression of lipogenic enzymes. We further demonstrate that insulin robustly upregulates Snaill which defines the noncanonical anti-lipogenic pathway. Thus, this work unravels a bifurcation of insulin signaling into the canonical lipogenic and the noncanonical anti-lipogenic arms.

\section{Results}

Insulin upregulates hepatic Snaill via PI 3-kinase pathway. Given that insulin stimulates Snaill expression in adipocytes ${ }^{11}$, we postulated that insulin might similarly upregulate Snaill in hepatocytes. Indeed, insulin markedly increased Snail1 mRNA levels in both mouse primary hepatocytes and human HepG2 hepatocytes (Supplementary Fig. 1a, b), and substantially increased Snaill protein levels in HepG2 hepatocytes (Fig. 1a). Likewise, insulin markedly increased the mRNA and protein levels of hepatic Snail1 in C57BL/6 mice (Supplementary Fig. 1c, d). Consistently, liver Snail1 levels were lower in the fasted state (low plasma insulin levels) than in the fed state (Supplementary Fig. 1e). To identify pathways responsible for upregulation of hepatic Snail1, we pretreated HepG2 hepatocytes with PI 3-kinase (wortmannin) or Akt (MK2066) inhibitors. Inhibition of either PI 3-kinase or Akt blocked upregulation of Snail1 by insulin (Fig. 1a and Supplementary Fig. 1f). Notably, Akt2 was reported to mediate TFG $\beta 1$-induced upregulation of Snail $1^{21}$. These data suggest that the PI 3-kinase/Akt pathway is required for insulin to upregulate hepatic Snaill.
Given that GSK3 $\beta$ induces ubiquitination and degradation of Snail1 $1^{22,23}$, we speculated that insulin might suppress proteasome-mediated degradation of Snaill via GSK3 $\beta$. Insulin stimulated phosphorylation and inactivation of GSK3 $\beta$ (Fig. 1a), confirming that insulin inhibits GSK3 $\beta$ via the PI 3kinase/Akt pathway ${ }^{24}$. First, we assessed Snaill stability in HepG2 hepatocytes using protein synthesis inhibitor cycloheximide. Insulin profoundly inhibited degradation of Snail1 (Fig. 1b). Half-life of Snaill was prolonged from $0.8 \mathrm{~h}$ in PBS-treated cells to $2.4 \mathrm{~h}$ in insulin-stimulated cells (Fig. 1c). Second, we measured ubiquitination of Snaill. We did not detect ubiquitinated Snail 1 in DMSO-treated HepG2 cells (Fig. 1d), presumably due to rapid degradation. Hence, we blocked degradation by pretreating cells with proteasome inhibitor MG132. We detected robust ubiquitination of Snail1; importantly, insulin dramatically decreased the levels of ubiquitinated Snaill (Fig. 1d).

We asked if the insulin/Snail 1 axis is impaired in obesity, owing to insulin resistance. C57BL/6 mice were fed a high fat diet (HFD) for 6 weeks to induce obesity. Insulin treatment substantially increased hepatic Snaill levels in chow-fed mice but not in HFD-fed mice (Fig. 1e and Supplementary Fig. 1g). To validate these findings in vitro, we pretreated HepG2 hepatocytes with palmitic acid to model metabolic environments in obesity. Palmitic acid pretreatment abrogated the ability of insulin to upregulate Snail1 (Fig. 1e and Supplementary Fig. 1h, i). Thus, the hepatic insulin/Snaill axis is impaired in obesity.

Insulin/Snail1 axis suppresses hepatic lipogenesis. We sought to delineate the role of the insulin/Snaill axis in hepatic lipogenesis. To disrupt this axis, we generated inducible, hepatocyte-specific Snail1 knockout (Snail1 ${ }^{\Delta h e p}$ ) mice by crossing Snail flox/flox mice with albumin-CreER ${ }^{T 2}$ drivers ${ }^{25,26}$ Snailiflox/flox;CreER ${ }^{T 2}$ mice were treated with tamoxifen to obtain Snail1 ${ }^{\Delta h e p}$ mice. Snail1 flox/flox littermates were treated similarly with tamoxifen as control. Snail1 was disrupted in the livers but not white adipose tissue (WAT) of Snail1 ${ }^{\Delta h e p}$ mice (Supplementary Fig. 2a). We assessed lipogenesis in primary hepatocytes isolated from Snail1 ${ }^{\Delta h e p}$ and Snail1 flox/flox mice. Deletion of Snail1 substantially increased the ability of insulin to stimulate lipogenesis (Fig. 2a), and caused an upward shift in insulin dose response curves (Supplementary Fig. 2b). To corroborate these findings, we measured expression of key lipogenic enzymes Fasn, Acc1, and Acl. Snaill deficiency markedly enhanced the ability of insulin to increase both mRNA (Fig. 2b) and protein (Fig. 2c) levels of these enzymes. Given upregulating Snail1 by insulin, these results unveil that the insulin/ Snail1 axis inhibits lipogenesis in a feedforward manner.

To further confirm the antagonistic effect of the insulin/Snail 1 axis on lipogenesis, we overexpressed Snail1 in primary hepatocytes using Snaill adenoviral vectors. Green fluorescent protein (GFP) vectors were used as control. Overexpression of Snaill completely blocked insulin-stimulated lipogenesis; notably, it also decreased baseline lipogenesis (Fig. 2d). In agreement with these results, Snaill blocked insulin-stimulated expression of Fasn, Acc1, and Acl (Fig. 2e, f). Notably, Snaill did not inhibit insulin-stimulated phosphorylation of Akt (Supplementary Fig. 2c), further supporting the notion that the insulin/Snail 1 axis suppresses lipogenesis via a feedforward circuit. Snaill did not alter the ability of insulin to suppress gluconeogenesis in primary hepatocytes (Supplementary Fig. 2d), suggesting that the insulin/Snaill axis specifically regulates lipid but not glucose metabolism in hepatocytes. In light of these findings, we propose that insulin signaling bifurcates into the canonical (lipogenic) and the noncanonical Snail1 (anti-lipogenic) arms. 

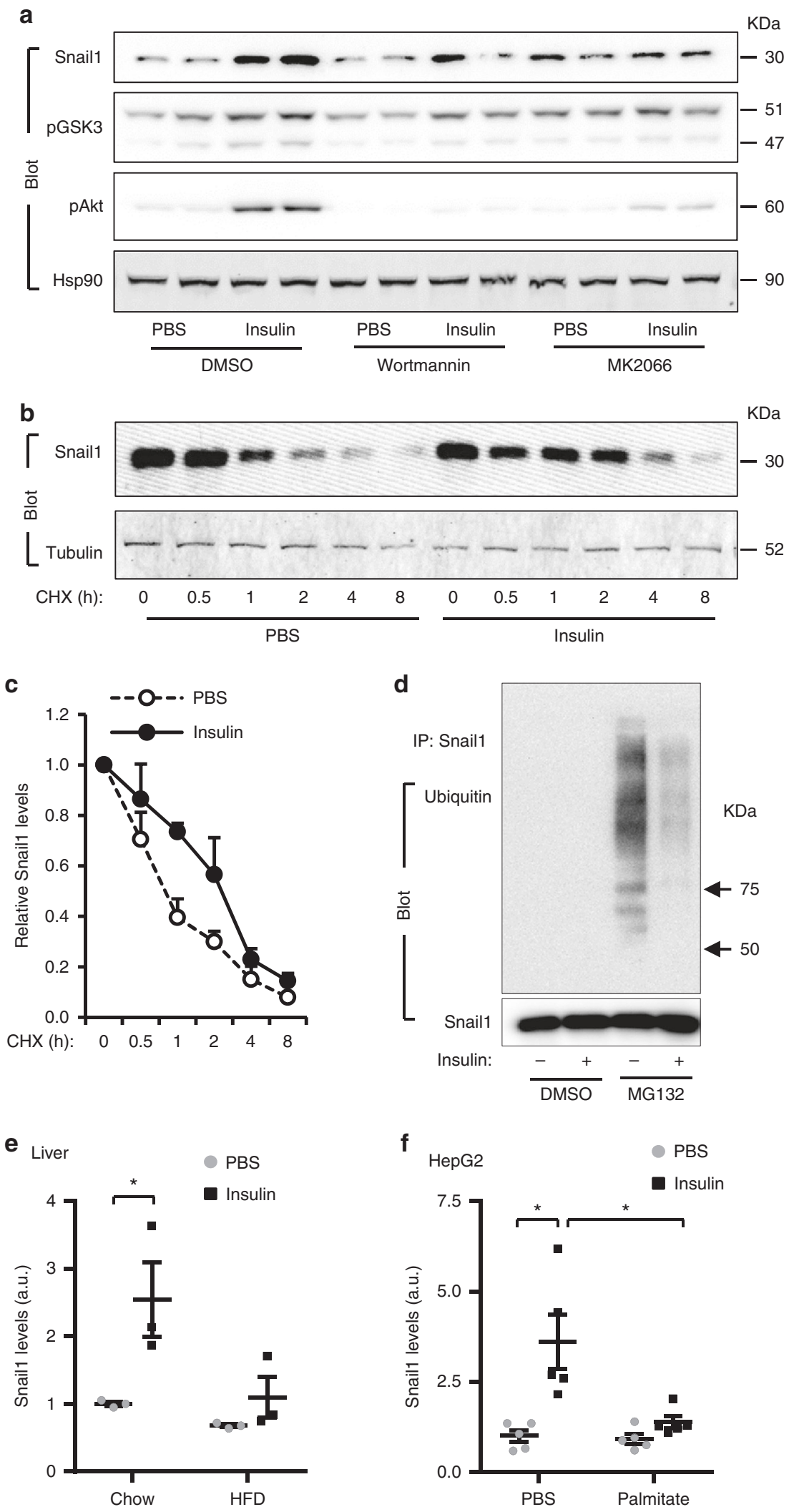

Hepatocyte-specific deletion of Snail1 promotes NAFLD. We set out to explore the function of the noncanonical Snaill arm in vivo by characterizing Snail ${ }^{\Delta h e p}$ mice. Snail1 ${ }^{\Delta h e p}$ mice were grossly normal. Body weight and plasma triacylglycerol (TAG) and nonesterified fatty acids (NEFA) were comparable between
Snail ${ }^{\text {Shep }}$ and Snail1 floxflox littermates (Supplementary Fig. 3a, b). Hepatocyte lipid droplets were larger and more abundant in Snail ${ }^{\Delta h e p}$ mice relative to Snail $1_{\text {floxfflox }}$ littermates, as assessed by staining liver sections with neutral lipid dye Nile red (Fig. 3a). Consistently, liver TAG levels were significantly higher in 
Fig. 1 Insulin upregulates hepatic Snail1 via the PI 3-kinase pathway. a HepG2 cells were pretreated with wortmannin or MK2066, and then stimulated with insulin for $2 \mathrm{~h}$. Cell extracts were immunoblotted with the indicated antibodies. Snail1 levels were normalized to Hsp90 levels $(n=4)$. b, c HepG2 cells were transfected with Snail1 plasmids and stimulated with insulin in the presence of cycloheximide. Cell extracts were immunoblotted with antibodies against Snail1 or $\alpha$-tubulin. Snail1 levels (normalized to $\alpha$-tubulin levels) were plotted against cycloheximide treatment durations $(n=3)$. $\mathbf{d}$ HepG 2 cells were transduced with Snail1 adenoviral vectors and stimulated with insulin with or without MG132 $(5 \mu \mathrm{M})$. Cell extracts were immunoprecipitated with antibody against Snail1 and immunoblotted with antibodies against ubiquitin or Snail1. e C57BL/6 males were fed a HFD or chow diet for 6 weeks, fasted overnight $(14 \mathrm{~h})$, and stimulated with insulin for $2 \mathrm{~h}$. Liver nuclear extracts were immunoblotted with antibodies against Snail1 or lamin A/C. Snail1 levels were normalized to lamin A/C levels $(n=3)$. $\mathbf{f} \mathrm{HepG} 2$ cells were pretreated with palmitate overnight and then stimulated with insulin. Cell extracts were immunoblotted with antibodies against Snail1 or Hsp90. Snail1 levels were quantified and normalized to Hsp90 levels $(n=4)$. Data are presented as mean \pm SEM. ${ }^{\star} p<0.05$, two-tailed unpaired Student's $t$ test

Snail ${ }^{\Delta h e p}$ mice (Fig. 3b). To extend these findings in obesity, we placed Snail1 ${ }^{\text {Shep }}$ and Snail1 flox/flox mice on a HFD for 10 weeks. Hepatocyte lipid droplets were substantially more abundant in Snail1 $1^{\Delta \text { hep }}$ mice relative to Snail1 flox/flox littermates (Fig. 3c). Liver TAG levels were significantly higher in Snail1 ${ }^{\Delta h e p}$ mice (Fig. 3d), although body weight and plasma TAG and NEFA levels were comparable between Snail1 $1^{\text {Shep }}$ and Snail1 flox/flox mice (Supplementary Fig. 3c, d).

To address concerns about the potential effect of tamoxifen on the observed phenotypes, we generated an independent line of Snail1 ${ }^{\text {thep }}$ mice by crossing Snail1 flox/flox mice with albumin-Cre drivers. These mice were fed a HFD for $10 \mathrm{wks}$, and body weight was comparable between sex-matched Snail1 ${ }^{\text {Shep }}$ and Snail1 flox/flox mice (Supplementary Fig. 3e). Liver TAG levels were significantly higher in Snail1 ${ }^{\Delta h e p}$ males and females relative to sex-matched Snail1 flox/flox $^{\text {littermates (Supple- }}$ mentary Fig. 3f). Additionally, we deleted hepatocyte Snail1 in adult Snailiflox/flox mice using adeno-associated virus (AAV) Cre vectors $^{27}$. Snail $1^{\text {flox/flox }}$ mice were fed a HFD for 6 weeks and then transduced with AAV-TBG-Cre or AAV-TBG-GFP (control) vectors. Snail1 was deleted in the livers but not the WAT of AAVTBG-Cre-transduced mice (Supplementary Fig. 3g). Hepatocyte lipid droplets were more abundant and larger (Fig. 3e), and liver TAG levels were significantly higher in AAV-TBG-Cre mice relative to AAV-TBG-GFP mice (Fig. 3f). Body weight was similar between these two groups (Supplementary Fig. 3h). Furthermore, deletion of hepatocyte Snail1 similarly exacerbated fructose-induced liver steatosis in Snail1 ${ }^{\Delta h e p}$ mice relative to Snaily flox/flox mice (Fig. 3g, h). Taken together, these data suggest that suppression of the noncanonical Snaill arm exacerbates NAFLD independently of changes in body weight.

Liver-specific expression of Snail1 protects against NAFLD. We reasoned that enhancing the hepatic insulin/Snaill arm might inhibit liver lipogenesis and NAFLD progression. C57BL/6 mice were fed a HFD for 7 weeks and transduced with Snaill (GFP as control) adenoviral vectors. Recombinant Snaill was detected in the liver but no other tissues as expected (Fig. 4a). Although body weight was comparable between Snaill and GFP adenoviraltransduced mice (Fig. 4b), hepatocyte lipid droplets were considerably smaller and less abundant in Snail1 adenoviraltransduced mice (Fig. 4c). Liver TAG levels were significantly lower in Snail1 than in GFP mice (Fig. 4d). Likewise, liver-specific overexpression of Snaill attenuated liver steatosis in $o b / o b$ mice with genetic obesity (Fig. 4e, f). These data suggest that the insulin/Snaill arm puts a brake on lipogenesis, thereby protecting against liver steatosis and lipotoxicity.

Hepatic Snail1 suppresses liver lipogenesis in vivo. To confirm inhibition of lipogenic programs by the Snaill arm in vivo, we measured hepatic levels of key lipogenic enzymes Fasn, Acc1, and
Acl in Snail1 ${ }^{\Delta h e p}$ mice fed a chow diet. Deletion of hepatic Snail1 substantially increased both mRNA (Fig. 5a) and protein (Fig. 5b) levels of these enzymes in Snail1 ${ }^{\text {thep }}$ mice compared to Snail $1^{\text {flox/ }}$ flox littermates. To extend these findings to NAFLD, we placed Snail1 flox/flox mice on a HFD for 6 weeks, followed by transduction with AAV-TBG-Cre (delete hepatic Snail1) or AAV-TBGGFP (control) vectors. Deletion of hepatocyte Snail1 markedly increased both mRNA and protein levels of liver Fasn, Acc1, and Acl (Fig. 5c, d). We also performed an unbiased gene expression profiling analysis, and found that expression of lipogenic genes as well as genes encoding lipid droplet proteins was higher in mice with hepatocyte-specific ablation of Snail1 (Supplementary Fig. 4a). In contrast, expression of the genes that control lipid uptake, fatty acid $\beta$ oxidation, and VLDL secretion was relatively normal (Supplementary Fig. 4a). Consistently, liver-specific overexpression of Snaill did not alter expression of the genes controlling $\beta$ oxidation and VLDL secretion (Supplementary Fig. 4b). Thus, protection against NAFLD by hepatic Snaill can be explained, at least in part, by reduction in liver de novo lipogenesis. To further test this notion, C57BL/6 mice were fed a HFD for 6 weeks (increasing baseline lipogenesis) and transduced with Snail1 (overexpressing Snail1 in the liver) or GFP (control) adenoviral vectors. Overexpression of Snaill profoundly decreased both mRNA and protein levels of Fasn, Acc1, and Acl in the liver (Fig. 5e, f). In contrast, expression of the genes that control liver inflammation (TNF $\alpha, I L 6, M C P 1, F 4 / 80)$, fibrosis (Fn1, vimentin, $\alpha S M A$, Colla 1a1), and EMT (Ecad, Cldh1) were similar between these two groups (Supplementary Fig. 4b).

Given Srebp-1c mediating insulin stimulation of lipogenesis, we tested if Snaill counteracts Srebp-1c action. Deletion of hepatic Snail1 upregulated Srebp-1c in the liver; conversely, liverspecific overexpression of Snail1 downregulated hepatic Srebp-1c (Supplementary Fig. 5a, b). Srebp-1c potently stimulated Fasn promoter activity, as assessed by Fasn luciferase reporter assays; in contrast, Snaill suppressed Fasn promoter activity (Supplementary Fig. 5c). Deletion of the serum response element (SRE), referred to as Fasn $(\triangle S R E)$, completely abolished Srebp-1cstimulated activation of Fasn $(\triangle S R E)$; in contrast, Snail1 still suppressed Fasn $(\triangle S R E)$ activity (Supplementary Fig. 5d). Furthermore, Snaill decreased Srebp-1c-stimulated activation of the Fasn promoter (Supplementary Fig. 5e). These data further support the concept that the noncanonical Snaill arm counterbalances the canonical Srebp-1c lipogenic arm in response to insulin.

Snail1 suppresses lipogenesis by an epigenetic mechanism. We next sought to interrogate the genomic mechanism of Snail 1 action, using the Fasn gene as a prototype of Snaill targets. In mouse liver, Snaill directly bound to the Fasn promoter as detected by chromatin immunoprecipitation (ChIP) (Fig. 6a). Snaill directly inhibited Fasn promoter activity in HepG2 cells (Fig. 6b). These data further confirm that Snail1 is a transcriptional repressor of lipogenic genes. 

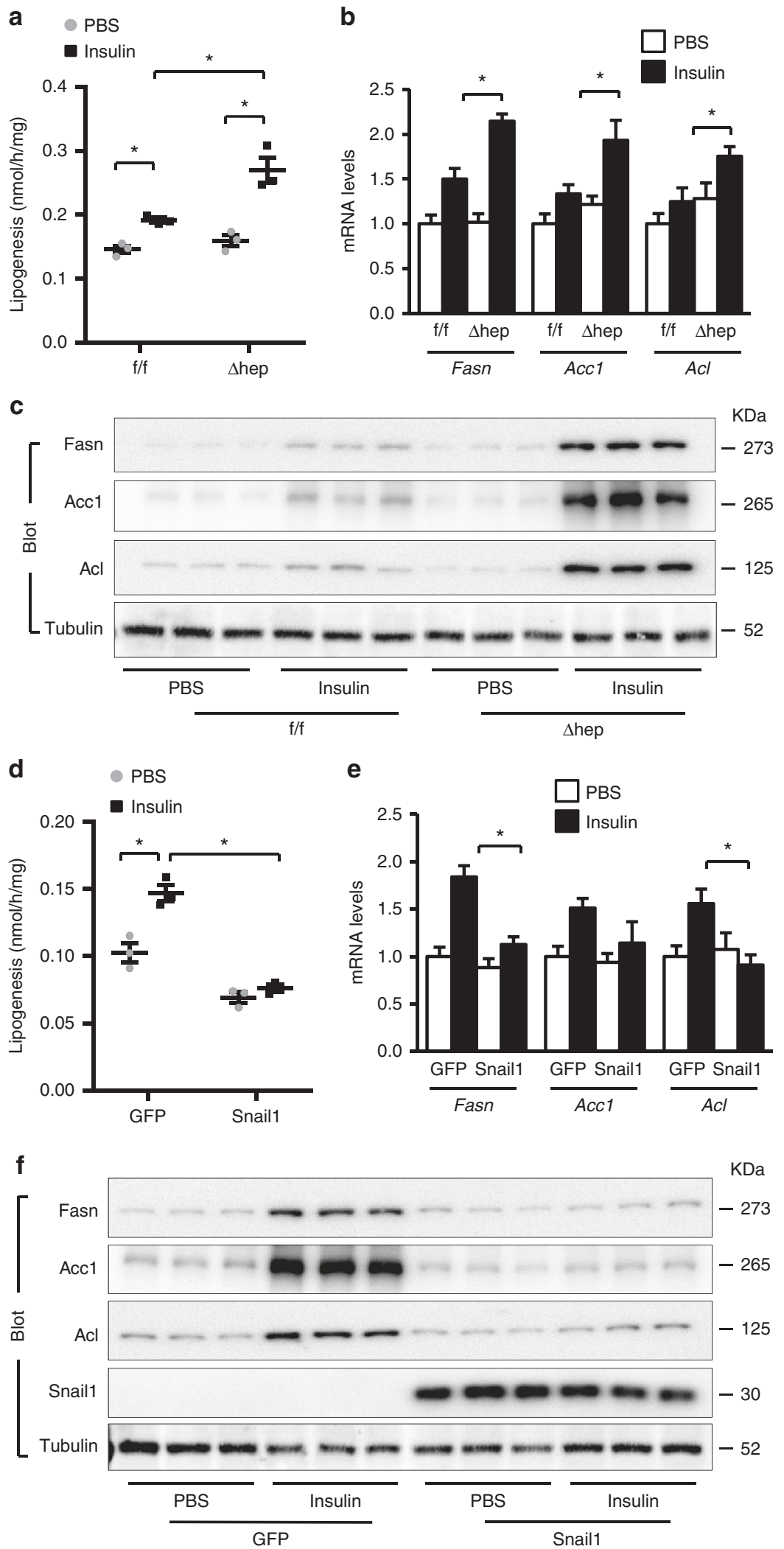

Fig. 2 Insulin/Snail1 axis suppresses de novo lipogenesis in hepatocytes. a-c Primary hepatocytes were isolated from Snail/ ${ }^{\text {hep }}$ and Snailflox/flox littermates and stimulated with insulin ( $50 \mathrm{nM}$ ) or PBS for $12 \mathrm{~h}(\mathbf{a}, \mathbf{c})$ or $4 \mathrm{~h}(\mathbf{b})$. a De novo lipogenesis assays (normalized to protein levels; $n=3$ ). b Fasn, Accl, and $\mathrm{Acl}$ mRNA levels (normalized to 36B4 levels; $n=4$ ). c Cell extracts were immunoblotted with the indicated antibodies. $\mathbf{d}$-f Primary hepatocytes were transduced with Snail1 or GFP adenoviral vectors and stimulated with insulin $(50 \mathrm{nM})$ for $12 \mathrm{~h}(\mathbf{d}, \mathbf{f})$ or $4 \mathrm{~h}(\mathbf{e})$. d De novo lipogenesis (normalized to protein levels; $n=3$ ). e Fasn, Acc1, and Acl mRNA levels (normalized to 36B4 levels; $n=4$ ). $\mathbf{f}$ Cell extracts were immunoblotted with the indicated antibodies. Data are presented as mean \pm SEM. ${ }^{*} p<0.05$ by two-tailed unpaired Student's $t$ test 
a

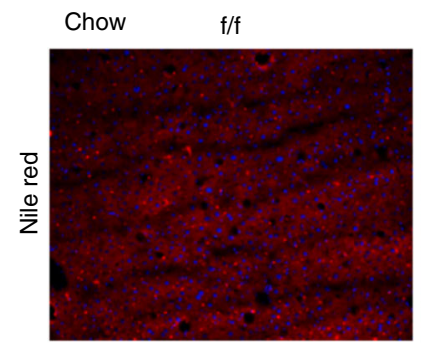

C

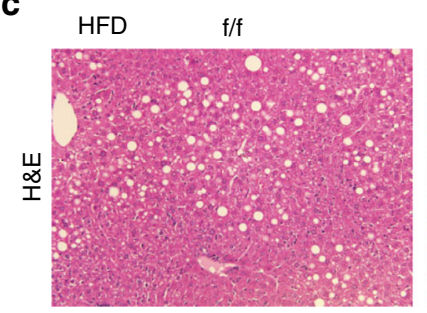

e
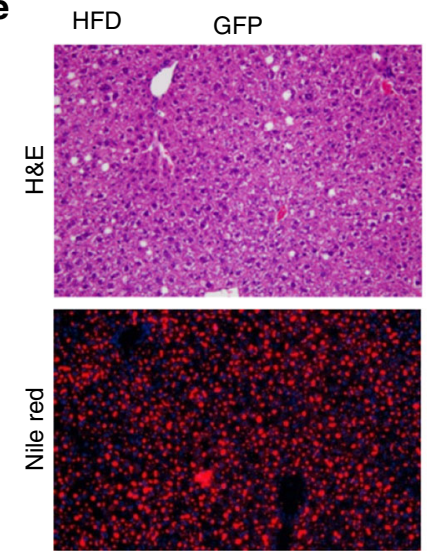

g

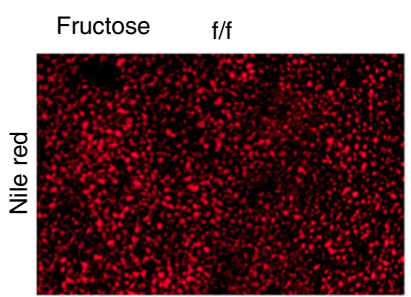

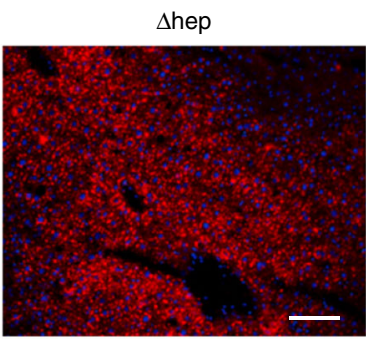

$\Delta$ hep

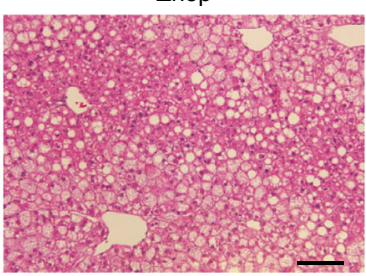

Cre
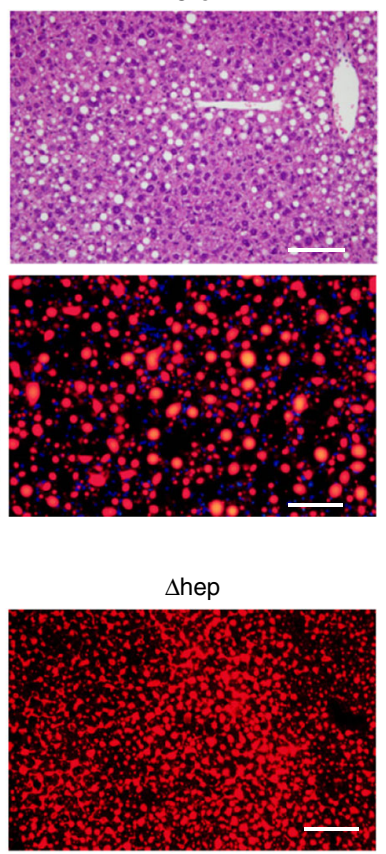

b

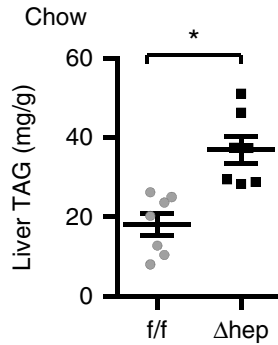

d

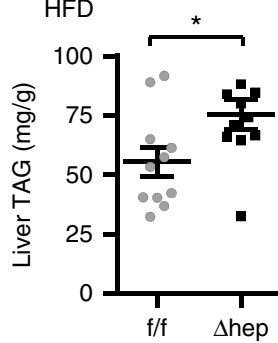

f HFD
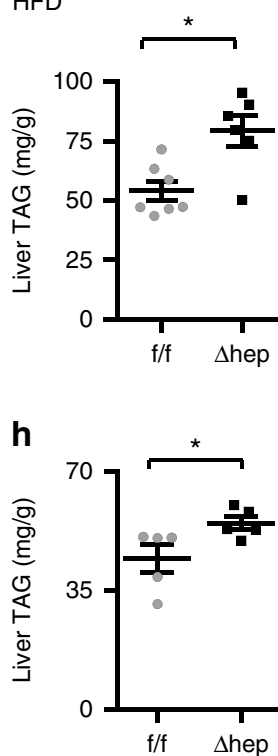

Fig. 3 Hepatocyte-specific deletion of Snail1 promotes NAFLD. a, b Snailflox/flox $(n=7)$ and Snail $7^{\Delta h e p}(n=7)$ males (18 weeks) were fed a normal chow diet. Livers were isolated under non-fasted conditions. a Representative Nile red staining of liver sections. b Liver TAG levels (normalized to liver weight). c, d Snailflox/flox $(n=11)$ and Snailthep $(n=11)$ male littermates were fed a HFD for 10 weeks. c Representative H\&E staining of liver sections. d Liver TAG levels (normalized to liver weight). e, f Snailfflox/flox males were fed a HFD for 6 weeks and transduced with AAV-TBG-GFP ( $n=7$ ) or AAV-TBG-Cre $(n=6)$ vectors for 4 weeks. e Representative H\&E or Nile red staining of liver sections. $\mathbf{f}$ Liver TAG levels (normalized to liver weight). $\mathbf{g}$, $\mathbf{h}$ Snailfflox/flox $(n=5)$ and Snail $7^{\text {Ahep }}(n=5)$ males were fed a fructose diet for 10 weeks. Scale bars: $100 \mu \mathrm{m}$. Data are represented as mean \pm SEM. ${ }^{*} p<0.05$, two-tailed unpaired Student's $t$ test

HDAC1 and HDAC2 have been known to repress expression of target genes by deacetylating histone $\mathrm{H} 3$ lysine-9 (H3K9) and H3K27, critical epigenetic modifications. We found that Snaill coimmunoprecipitated with both HDAC1 and HDAC2 in mouse liver (Fig. 6c). Hence, we measured acetylation of $\mathrm{H} 3 \mathrm{~K} 9$ (H3K9ac) and H3K27 (H3K27ac) on the Fasn promoter. Liverspecific overexpression of Snaill significantly reduced both $\mathrm{H} 3 \mathrm{~K} 9 \mathrm{ac}$ and H3K27ac levels in the liver (Fig. 6d). In contast, Snail1 did not alter the levels of $\mathrm{H} 3 \mathrm{~K} 9 \mathrm{ac}$ and $\mathrm{H} 3 \mathrm{~K} 27 \mathrm{ac}$ on unrelated $\mathrm{NCH}$ and Actb promoters (Fig. 6d). To extend these findings to endogenous Snaill, we assessed H3K9ac and H3K27ac levels in the livers of Snail1 ${ }^{\text {thep }}$ mice. Ablation of hepatic Snail1 markedly increased both H3K9ac and H3K27ac levels on the Fasn promoter in the livers of Snail1 ${ }^{\text {Shep }}$ mice relative to Snail $1^{\text {floxfflox }}$ littermates (Fig. 6e). Notably, other forms of histone modifications on the Fasn promoter, including trimethylation of $\mathrm{H} 3 \mathrm{~K} 4$, $\mathrm{H} 3 \mathrm{~K} 9$, and H3K27, were not altered by either overexpression or ablation of Snaill in the liver (Supplementary Fig. 6a, b).

To confirm inhibition of lipolysis by Snail1-elicited histone deacetylation, primary hepatocytes were transduced with Snail1 and treated with trichostatin A (TSA), a selective HDAC inhibitor. TSA blocked the ability of Snaill to inhibit lipogenesis 
a
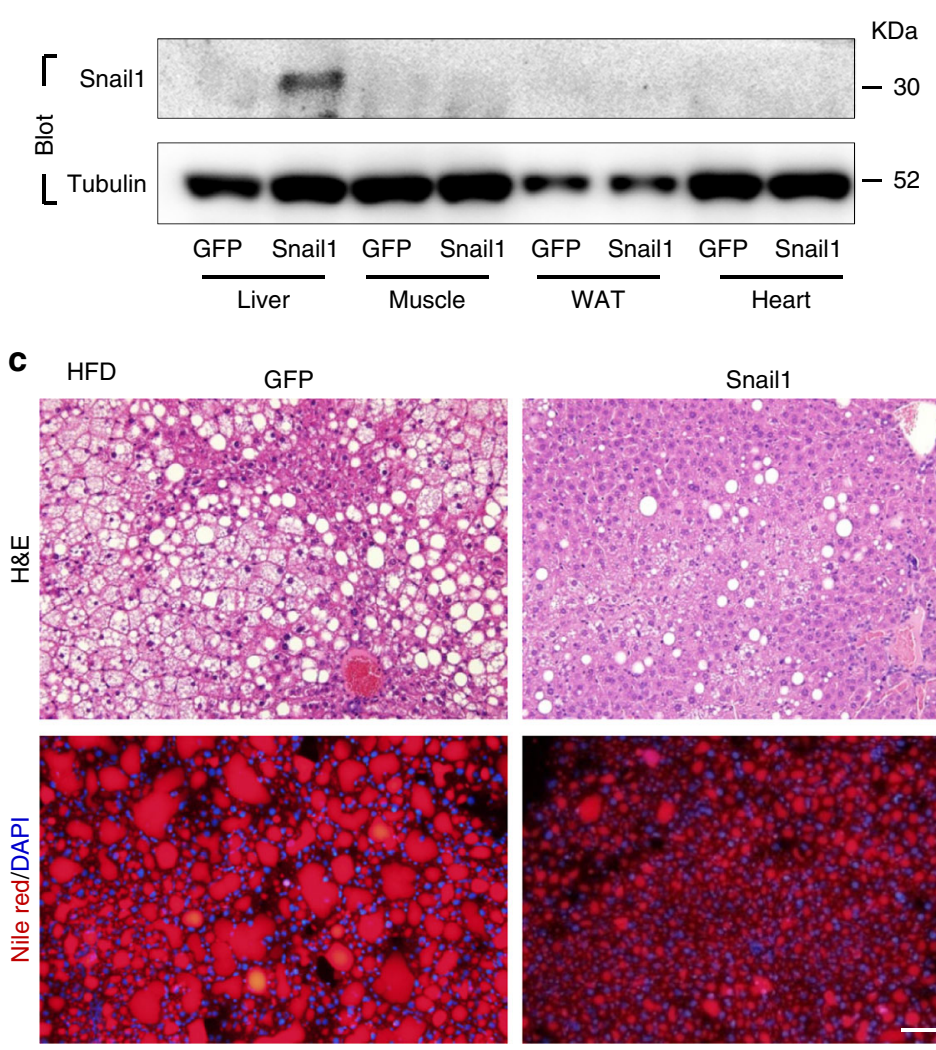

e $o b / o b$
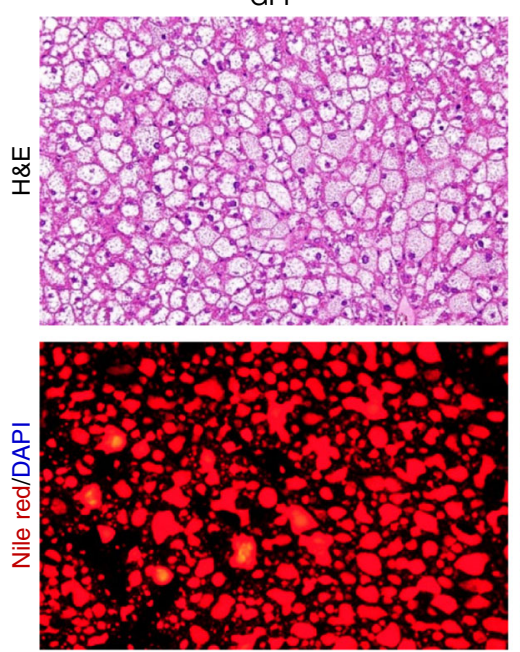
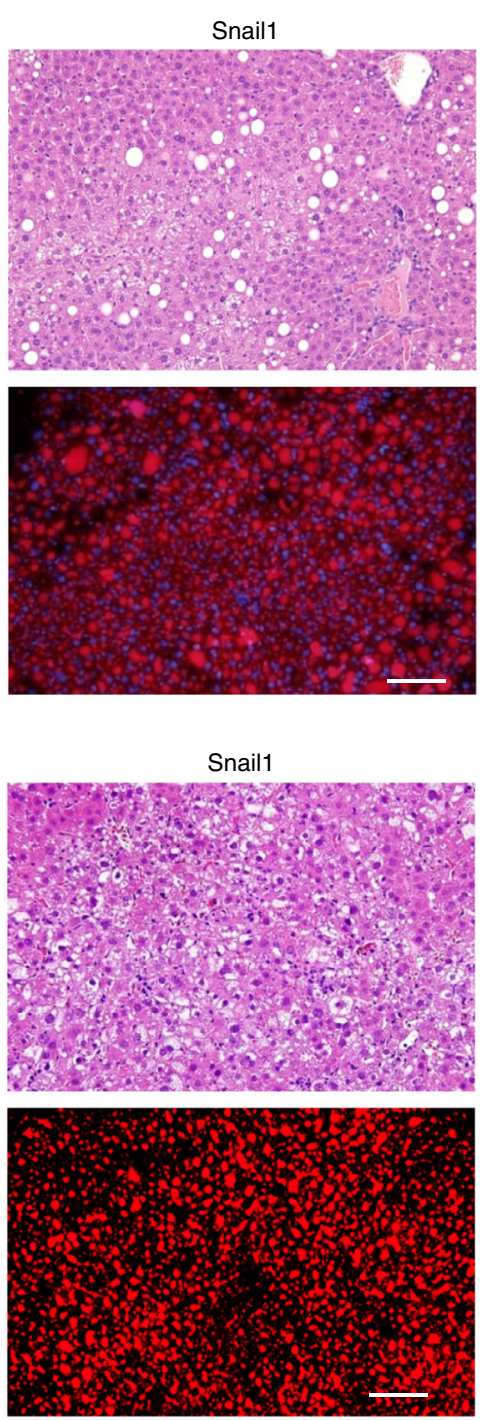

b

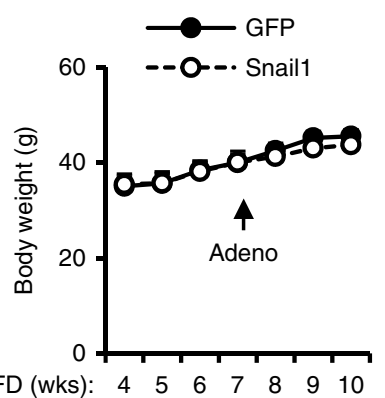

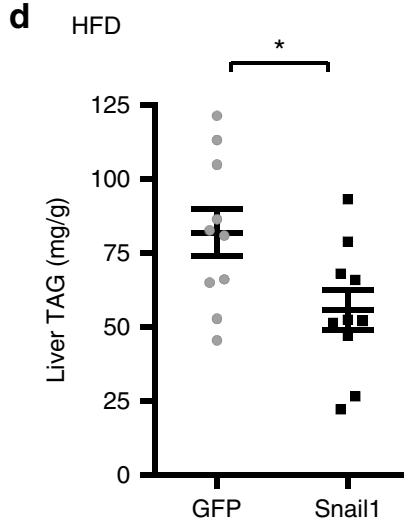

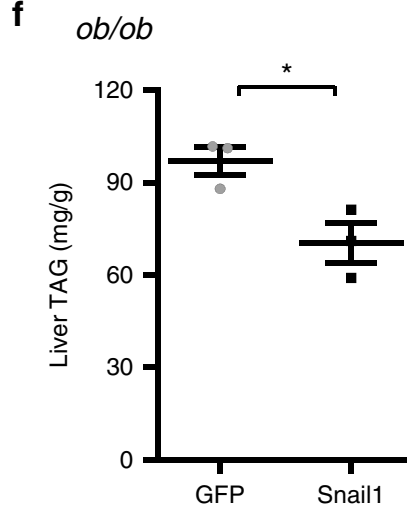

Fig. 4 Liver-specific overexpression of Snail1 protects against NAFLD. a-d C57BL/6 male mice (8-9 weeks) were fed a HFD for 7 weeks and transduced with Snail1 $(n=10)$ or GFP $(n=10)$ adenoviral vectors. Livers were harvested 3 weeks after transduction. a Tissue extracts were immunoblotted with the indicated antibodies. b Growth curves. c Representative H\&E or Nile red staining of liver sections. Scale bar: $100 \mu$ m. d Liver TAG levels (normalized to liver weight). e, fob/ob male mice ( 9 weeks) were transduced with GFP $(n=3)$ or Snail1 $(n=3)$ adenoviral vectors for 3 weeks. e Representative H\&E or Nile red staining of liver sections. $\mathbf{f}$ Liver TAG levels (normalized to liver weight). Scale bars: $100 \mu \mathrm{m}$. Data are presented as mean \pm SEM. ${ }^{\star} p<0.05$, two-tailed unpaired Student's $t$ test

(Supplementary Fig. 6c). TSA also reversed Snail1-induced suppression of Fasn expression (Supplementary Fig. 6d, e). To corroborate these findings, we deleted the SNAG domain of Snail1 (amino acids 1-20) responsible for binding to HDAC1/2, referred to as $\Delta$ N20. Primary hepatocytes were transduced with Snaill or $\Delta \mathrm{N} 20$ adenoviral vectors, followed by stimulation with insulin. $\Delta \mathrm{N} 20$, unlike Snail1, was unable to suppress insulin stimulation of Fasn expression (Supplementary Fig. 6f) and lipogenesis (Fig. 6f). Importantly, $\Delta \mathrm{N} 20$ also lost the ability to elicit deacetylation of H3K9 (Supplementary Fig. 6g) and H3K27 (Fig. 6g). Collectively, these data suggest that the insulin/Snail1 axis suppresses de novo lipogenesis through epigenetic reprogramming of lipogenic genes, particularly via deacetylating H3K9 and H3K27. 


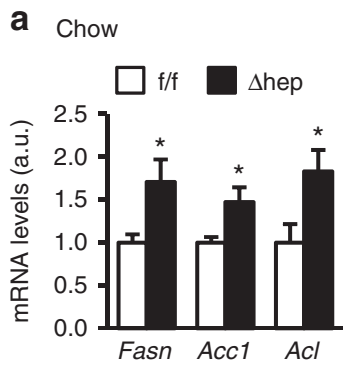

b
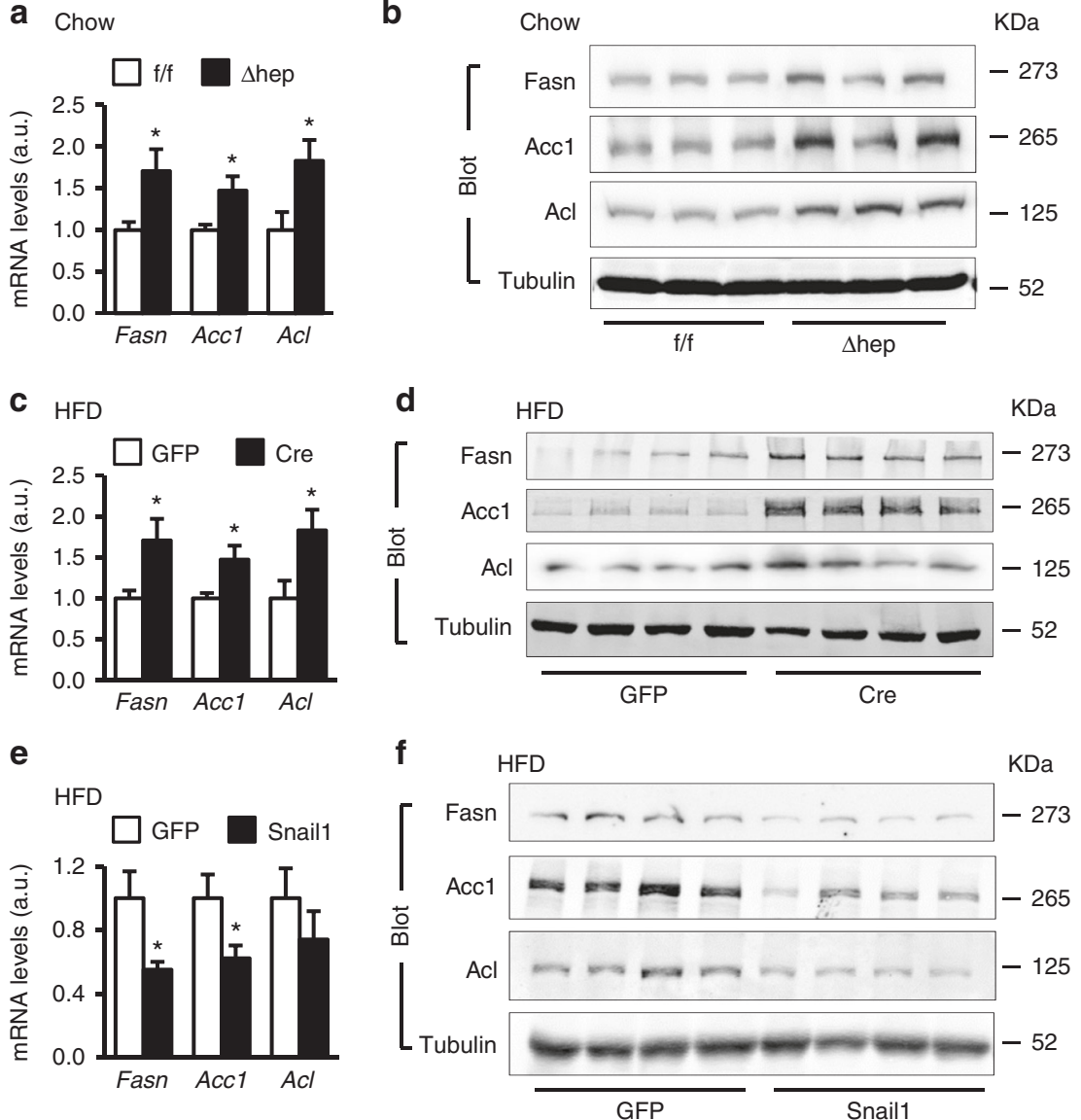

Fig. 5 Snail1 directly suppresses liver lipogenic programs in vivo. a, b Snail 1 hhep $(n=6)$ and Snailflox/flox $(n=6)$ males fed a normal chow diet for 18 weeks. c, $\mathbf{d}$ Snailflox/flox male mice (8-9 weeks) were fed a HFD for 6 weeks and transduced with AAV-TBG-GFP $(n=6)$ or AAV-TBG-Cre $(n=6)$ vectors. Livers were harvested 4 weeks after AAV transduction. e, f C57BL/6 male mice (8-9 weeks) were fed a HFD for 7 weeks and transduced with Snail1 ( $n=5$ ) or GFP ( $n=5)$ adenoviral vectors. e Liver Fasn, Acc1, and Acl expression was assessed by qPCR (normalized to $36 \mathrm{~B} 4$ expression). $\mathbf{f}$ Liver extracts were immunoblotted with the indicated antibodies. Fasn, Acc1, and Acl levels were quantified and normalized to $\alpha$-tubulin levels. Data are presented as mean \pm SEM. ${ }^{\star} p<0.05$, two-tailed unpaired Student's $t$ test

\begin{abstract}
Ablation of hepatic Snaill exacerbates insulin resistance. Liver steatosis has been thought to induce insulin resistance, prompting us to examine glucose metabolism in Snail1 ${ }^{\text {thep }}$ mice. Plasma insulin levels was normal in Snail1 ${ }^{\Delta h e p}$ mice fed a normal chow diet (Snail1 ${ }^{\Delta h e p}: 0.70 \pm 0.07 \mathrm{ng} / \mathrm{ml}, n=5$; Snail1 ${ }^{\text {flox}} /$ flox: $0.61 \pm$ $0.09 \mathrm{ng} / \mathrm{ml}, n=5 ; \mathrm{p}=0.42)$. We placed Snail1 ${ }^{\Delta h e p}$ and Snail $1^{\text {flox }}$ / flox littermates on a HFD for 10 weeks. Body weight was similar between these two groups (Supplementary Fig. 3c). Snail1 ${ }^{\Delta h e p}$ mice developed more severe hyperinsulinemia, a hallmark of systemic insulin resistance, relative to Snail1 $1^{\text {flox/flox }}$ littermates (Fig. 7a). To confirm insulin resistance, we performed insulin (ITT) and glucose (GTT) tolerance tests. Insulin had reduced ability to decrease blood glucose in Snail ${ }^{\Delta h e p}$ mice compared to Snaily flox/flox mice (Fig. 7b). The areas under the curves (AUC) of both ITT and GTT were significantly higher in Snail1 ${ }^{\Delta h e p}$ mice (Fig. 7b, c). Furthermore, the levels of insulin-stimulated phosphorylation of Akt (pSer473 and pThr308) in the liver was significantly lower in Snail1 ${ }^{\text {Shep }}$ than in Snailf flox/flox littermates (Fig. 7d). Thus, Snail1 ${ }^{\text {Shep }}$ mice are prone to both liver steatosis and insulin resistance.

To determine whether liver-specific overexpression of Snail1 has the opposite effect, C57BL/6 mice were fed a HFD for 7 weeks and transduced with Snaill or GFP (control) adenoviral vectors. Overexpression of Snaill significantly attenuated HFD-induced insulin resistance and glucose intolerance (Fig. 7e, f), although
\end{abstract}

body weight was similar between Snaill and GFP adenoviraltransduced mice (Fig. 4b). Concurrently, hepatic Snaill substantially decreased liver steatosis in obese mice (Fig. 4c). Together, these data suggest that the hepatic insulin/Snaill axis ameliorates insulin resistance in obesity, presumably through decreasing liver steatosis.

\section{Discussion}

In this study, we have identified hepatic Snaill as an unrecognized suppressor of lipogenesis. Snail1 bound to the promoters of lipogenic genes where it recruited $\mathrm{HDAC} 1 / 2$ to catalyze repressive deacetylation of $\mathrm{H} 3 \mathrm{~K} 9$ and $\mathrm{H} 3 \mathrm{~K} 27$. Insulin robustly upregulated hepatic Snaill in both primary hepatocytes and livers, defining an unrecognized noncanonical insulin/Snaill pathway that epigenetically suppresses lipogenesis.

In hepatocytes, insulin substantially increased both expression and stability of Snail1 in a PI 3-kinase-dependent manner, defining an insulin-PI 3-kinase-Snaill cascade. Snail1 overexpression blocked insulin-stimulated expression of lipogenic enzymes and lipogenesis in primary hepatocytes. Liver-specific overexpression of Snaill suppressed the hepatic lipogenic program and protected against dietary NAFLD. Conversely, ablation of hepatic Snaill, using three distinct approaches (tamoxifen, AAV-TBG-Cre, and albumin-Cre), had the opposite effect. These 
a

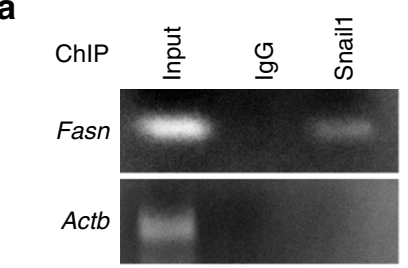

b
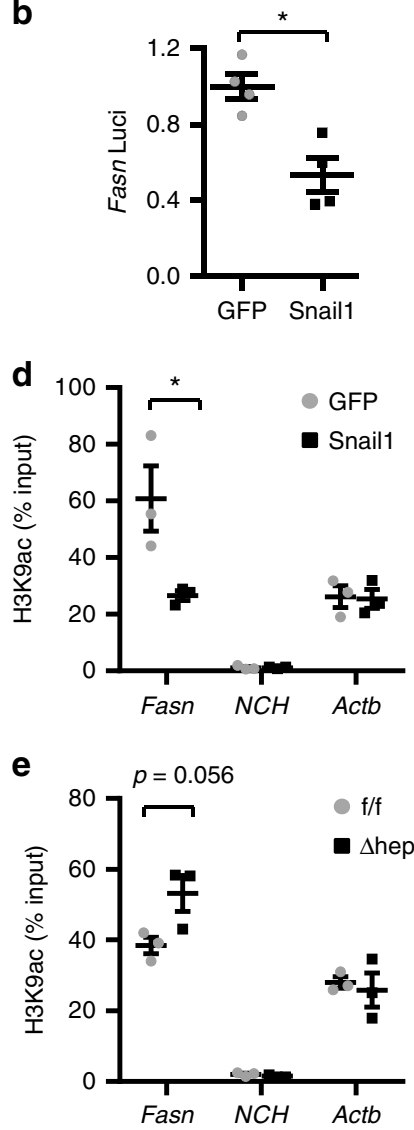

f
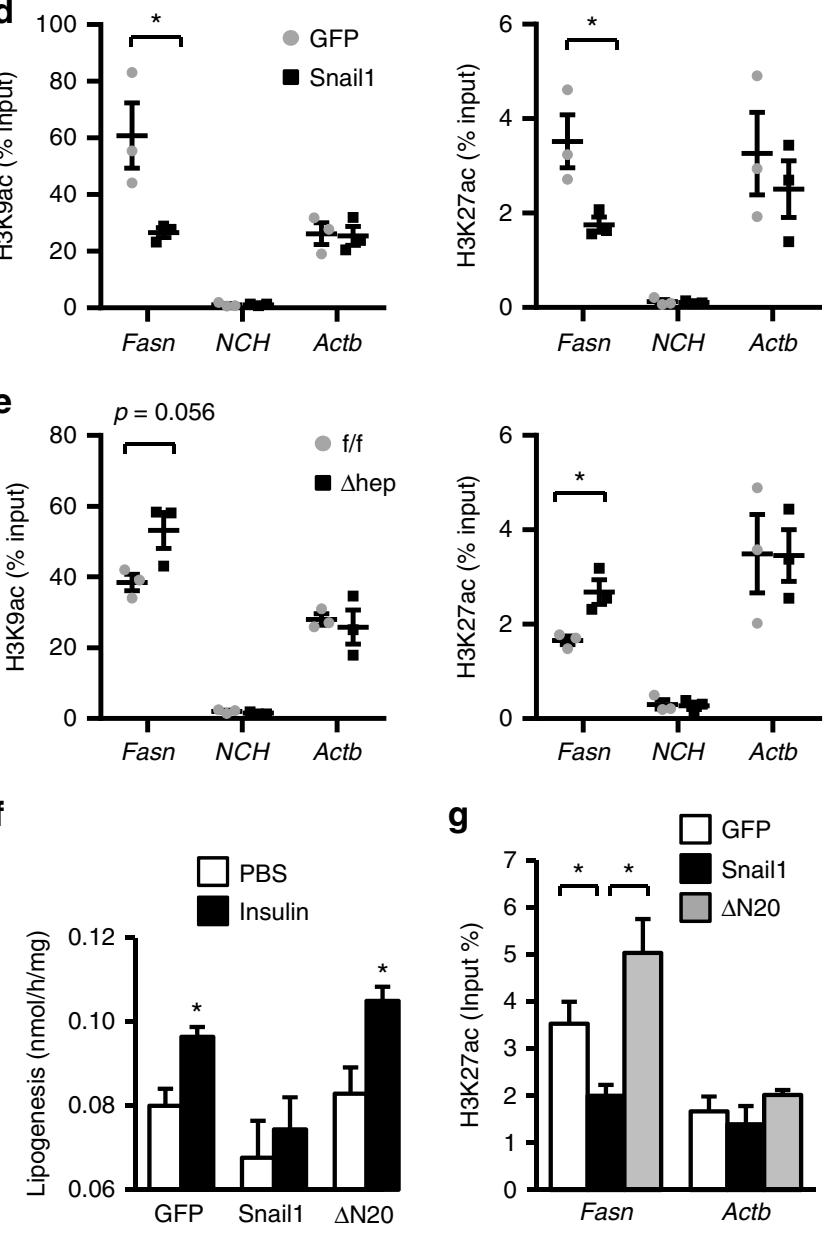

Fig. 6 Snail1 epigenetically represses the Fasn promoter. a Male mice were transduced with Snail1 adenoviral vectors for 3 weeks. Binding of Snail1 to the Fasn promoter was assessed in the liver by ChIP. b Fasn luciferase activity (normalized to $\beta$-gal internal controls). c Male mice were transduced with Snail1 adenoviral vectors for 3 weeks. Liver extracts were immunoprecipitated with antibody against Snail1 and immunoblotted with antibodies against HDAC1 or HDAC2. d C57BL/6 male mice (8-9 weeks) were fed a HFD for 7 weeks and then transduced with Snail $(n=3)$ or GFP $(n=3)$ adenoviral vectors. Livers were harvested 3 weeks after transduction. The levels of liver H3K9ac and H3K27ac on the Fasn, NCH, or Actb promoter were measured by ChIP-qPCR and normalized to inputs. e Snail ${ }^{\Delta h e p}(n=3)$ and Snailfflox/flox $(n=3)$ males were fed a HFD for 10 weeks. The levels of liver H3K9ac or H3K27ac on the Fasn, NCH, or Actb promoter were measured by ChIP. $\mathbf{f}, \mathbf{g}$ Primary hepatocytes were transduced with Snail1, $\Delta \mathrm{N} 2 \mathrm{O}$, or GFP adenoviral vectors and stimulated with or without insulin ( $50 \mathrm{nM}$ ) for $12 \mathrm{~h}$. $\mathbf{f}$ Lipogenesis. $\mathbf{g} \mathrm{H} 3 \mathrm{~K} 27 \mathrm{ac}$ levels on the Fasn promoter. Data are presented as mean \pm SEM. ${ }^{\star} p<0.05$, twotailed unpaired Student's $t$ test

mentioning that obesity is associated with compensatory hyperinsulinemia in part due to adipose insulin resistance. Hyperinsulinemia further drives hepatic lipogenesis, particular when liver is still sensitive to insulin and/or the Snaill arm is dysfunctional, thereby exacerbating NAFLD.

Mechanistically, we found that Snaill directly bound to the Fasn promoter and repressed Fasn promoter activity. Snail1 has been known to bind, via its SNAG domain, to many epigenetic enzymes, including HDAC1/2, LSD1, Ezh2, and G9a $15,16,32$. We confirmed that Snail1 bound to HDAC1/2 in the liver. Overexpression of Snaill decreased, whereas ablation of Snaill increased, the levels of $\mathrm{H} 3 \mathrm{~K} 9 \mathrm{ac}$ and $\mathrm{H} 3 \mathrm{~K} 27 \mathrm{ac}$, active epigenetic marks, on the Fasn promoter. Remarkably, inhibition of HDAC1/ 2 by TSA blocked Snaill-induced suppression of lipogenesis. Deleting the SNAG domain also abrogated the ability of Snail1 to inhibit insulin stimulation of lipogenesis. These findings support the notion that Snaill suppresses lipogenesis at least in part by recruiting $\mathrm{HDAC1} / 2$ to lipogenic gene promoters where HDAC1/ 2 catalyze repressive deacetylation of $\mathrm{H} 3 \mathrm{~K} 9$ and $\mathrm{H} 3 / \mathrm{K} 27$.

Given that liver steatosis is linked to insulin resistance, it is not unexpected that ablation of hepatic Snaill exacerbated, whereas liver-specific overexpression of Snaill ameliorated, HFD-induced insulin resistance and glucose intolerance. It is worth mentioning that simple liver steatosis has been reported to be dissociated from insulin resistance ${ }^{33}$. Diacylglycerol and several lipid species, rather than inert TAG, are able to induce insulin resistance ${ }^{34-37}$. In light of these observations, we propose that hepatic Snaill may selectively inhibit production of toxic lipid species that induce insulin resistance. Additional studies are needed to test this hypothesis in the future.

Liver steatosis is considered, historically, as the first hit during NAFLD development ${ }^{38}$. In the presence of the secondary and/or multiple other hits (e.g., oxidative stress), relatively benign fatty liver progresses to pathogenic NAFLD/NASH manifested by liver inflammation, injury, and fibrosis ${ }^{38,39}$. The severity of liver steatosis is influenced by multiple metabolic pathways, which are controlled largely at the transcriptional level. Transcription factors Srebp-1c, ChREBP, and Lxr have been extensively characterized for their ability to stimulate de novo lipogenesis and liver steatosis ${ }^{6,40-43}$. Hepatic PPAR $\gamma$, which is upregulated in obesity, stimulates expression of lipid droplet proteins as well as fatty acid transporters, thereby promoting liver steatosis ${ }^{8,44-48}$. In contrast, hepatic PPAR $\alpha, \operatorname{PPAR} \beta / \delta$, Foxa2, and circadian clock BMAL1 exert anti-steatosis action by promoting fatty acid $\beta$ oxidation $^{49-54}$. Recent studies have highlighted the impact of 
a

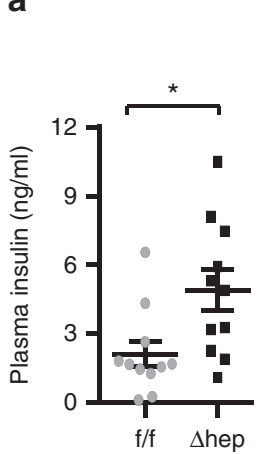

b

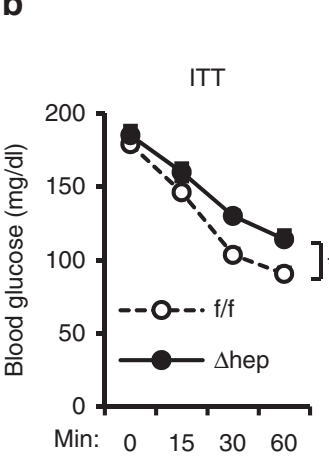

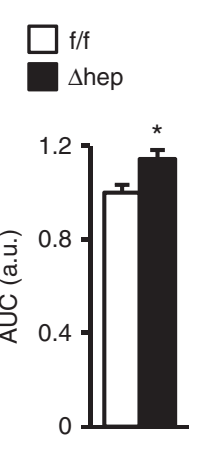

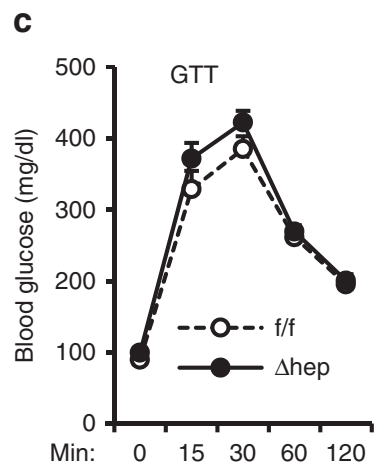

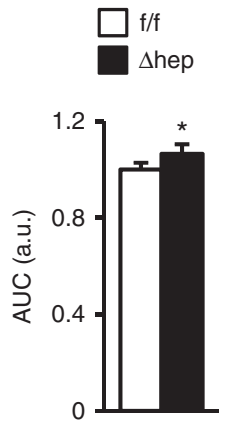

d
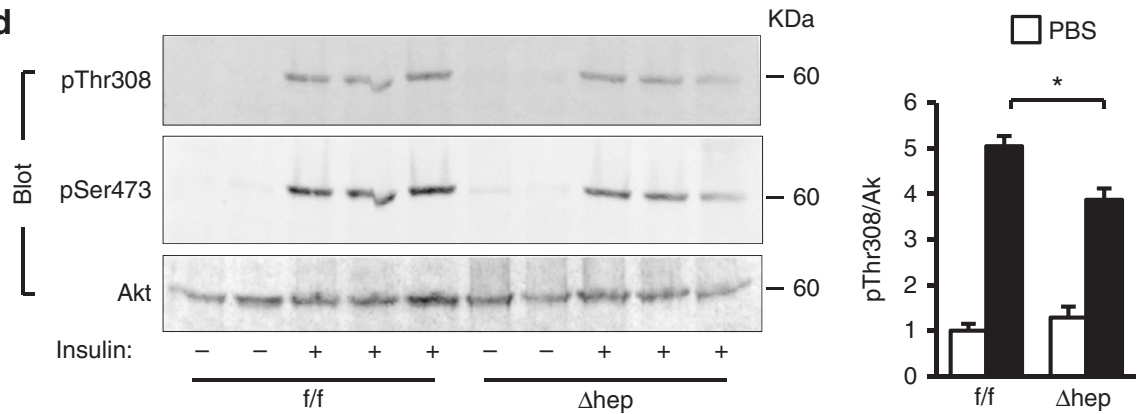

Insulin

e

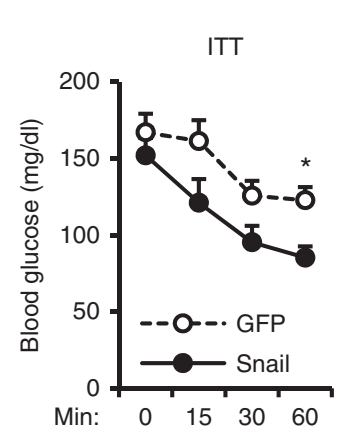

f
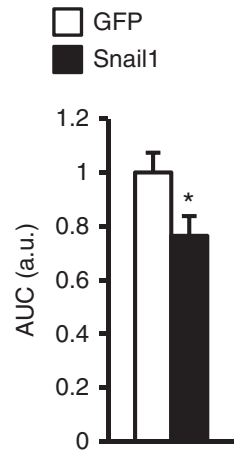

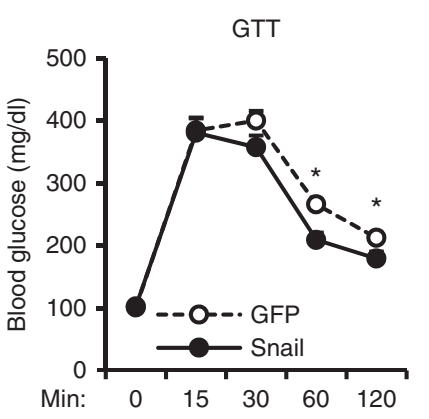

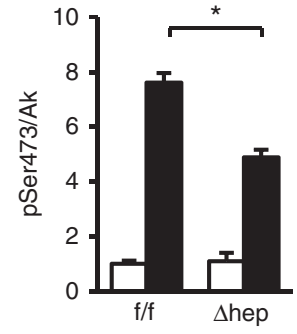

$\square$ GFP

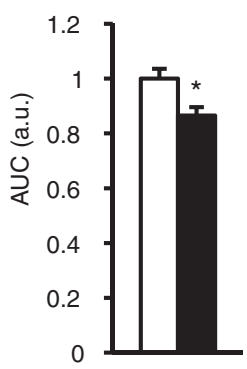

Fig. 7 Hepatic Snail1 ameliorates insulin resistance in obesity. a-d Snail ${ }^{\Delta h e p}(n=11)$ and Snailflox/flox $(n=11)$ male mice $(8-9$ weeks $)$ were fed a HFD for 10 weeks. a Overnight fasting plasma insulin levels. b ITT. AUC areas under curves. c GTT. d Mice were fasted overnight (14 h) and injected with insulin $(0.5$ units $/ \mathrm{kg}$ ). Liver extracts were prepared 5 min later and immunoblotted with anti-phospho-Akt (pSer473 or pThr308) or anti-Akt antibodies. Akt phosphorylation was normalized to total Akt levels. e, $\mathbf{f}$ C57BL/6 male mice (8-9 weeks) were fed a HFD for 7 weeks and transduced with Snail1 ( $n=10$ ) or GFP $(n=10)$ adenoviral vectors for 2 weeks after transduction. e ITT. f GTT. Data are presented as mean \pm SEM. ${ }^{*} p<0.05$, two-tailed unpaired Student's $t$ test

negative regulators of lipogenesis on NAFLD. Fxr, nuclear receptors for bile acids, suppresses lipogenesis and liver steatosis $^{55-57}$. Circadian clock Rev-erb $\alpha / \beta$ also suppresses lipogenesis, and liver-specific ablation of rev-erb $\alpha / \beta$ results in NAFLD ${ }^{58,59}$. Notably, in contrast to genetic lipogenic programs that have been extensively investigated, epigenetic regulation of lipid metabolism remains largely unclear. In this regard, Snail1-elicited epigenetic reprogramming of hepatic lipogenesis, identified in this study, likely points to a new direction in the NAFLD field.

In conclusion, we have unveiled the noncanonical insulinSnaill pathway that epigenetically suppresses hepatic lipogenesis. Impairment in this pathway increases hepatic de novo lipogenesis, contributing to NAFLD in obesity. Our data suggest that the insulin/Snail1/epigenetic axis may serve as a potential therapeutic target for the treatment of NAFLD and metabolic disease.

\section{Methods}

Animal treatments. Animal experiments were conducted following the protocols approved by the University of Michigan Institutional Animal Care and Use
Committee (IACUC). Snail1 flox/flox and albumin-CreER ${ }^{T 2}$ mice (C57BL/6 background) have been characterized previously ${ }^{25,26}$. Mice were housed on a 12 -h lightdark cycle in the Unit for Laboratory Animal Medicine at the University of Michigan (ULAM), and fed ad libitum either a normal chow diet ( $9 \%$ fat in calories; TestDiet, St. Louis, MO), a HFD (60\% fat in calories; Research Diets, New Brunswick, NJ), or a fructose diet (60\% Fructose; in calories; Research Diets, New Brunswick, NJ).

To generate mice hepatocyte-specific ablation of Snail1, Snail $1^{\text {flox/flox }}$ mice were

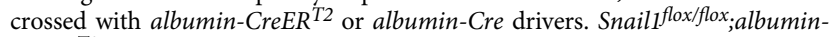
$\mathrm{CreER}^{T 2}$ mice were intraperitoneally injected with tamoxifen (Cayman) $(0.5 \mathrm{mg} /$ mouse, twice 2 days apart) to obtain Snail1 ${ }^{\text {Shep }}$ mice. Snail1 ${ }^{\text {flox/flox }}$ mice were similarly treated with tamoxifen as control. Alternatively, adult Snaily flox/flox mice were fed a HFD for 6-7 wks and injected with AAV-TBG-Cre or AAV-TBG-GFP vectors via tail veins $\left(10^{11}\right.$ viral particles/mouse). To generate mice with liverspecific overexpression of Snail1, C57BL/6 male mice (12 wks) were fed a HFD for 6 weeks and then transduced with Snail1 or GFP (control) adenoviral vectors via tail vein injection ( $10^{11}$ viral particles/mouse). ob/ob mice $(9 \mathrm{wks})$ were similarly transduced with Snaill or GFP adenoviral vectors.

To measure liver Snaill levels, C57BL/6 males (8-10 wks) were fed a HFD or chow diet for 6 weeks, fasted overnight $(14 \mathrm{~h})$, and stimulated with insulin ( 0.75 units $/ \mathrm{kg}$ body weight, i.p.) for $2 \mathrm{~h}$. Liver nuclear extracts were prepared and immunoblotted with antibodies against Snaill or lamin A/C (loading control). 
Glucose (GTT) and insulin (ITT) tolerance tests. Mice were fasted overnight (GTT) or for $6 \mathrm{~h}$ (ITT), and intraperitoneally injected with glucose $(1 \mathrm{~g} / \mathrm{kg}$ body weight) for GTT or human insulin ( 1 unit/kg body weight) for ITT. Blood glucose was measured in tail veins $0,15,30,60$, and 120 min after injection. Plasma insulin levels were measured using mouse insulin ELISA kits (CRYSTAL CHEM, Downers Grove, IL).

Nile red staining and liver TAG levels. Liver frozen sections were fixed with $4 \%$ paraformaldehyde for $20 \mathrm{~min}$, washed twice with PBS, stained with Nile red $(1 \mu \mathrm{g} /$ $\mathrm{ml}$ in PBS) for $\sim 30 \mathrm{~min}$, washed twice with PBS, and visualized using fluorescent microscope. Liver samples were homogenized in $1 \%$ acetic acid, and lipids were extracted using $80 \%$ chloroform/Methanol (2:1). Organic fractions were dried in a chemical hood, resuspended in a $\mathrm{KOH}(3 \mathrm{M}) /$ ethanol solution, incubated at $70^{\circ} \mathrm{C}$ for $1 \mathrm{~h}$, mixed with $\mathrm{MgCl}_{2}(0.75 \mathrm{M})$, and centrifuged. Aqueous fractions were used to measure TAG levels using Free Glycerol Reagent (Sigma)

Immunoblotting and immunoprecipitation. Tissues or cells were homogenized in a lysis buffer $(50 \mathrm{mM}$ Tris $\mathrm{HCl}, \mathrm{pH}$ 7.5, 1.0\% NP-40, $150 \mathrm{mM} \mathrm{NaCl}, 2$ mM EGTA, $1 \mathrm{mM} \mathrm{Na} \mathrm{VO}_{4}, 100 \mathrm{mM} \mathrm{NaF}, 10 \mathrm{mM} \mathrm{Na} \mathrm{P}_{2} \mathrm{O}_{7}, 1 \mathrm{mM}$ PMSF, $10 \mathrm{mg} / \mathrm{ml}$ aprotinin, and $10 \mathrm{mg} / \mathrm{ml}$ leupeptin). Tissue or cell extracts were immunoprecipitated and/or immunoblotted with the indicated antibodies (Supplementary table 1). Uncropped scans of important blots were provided in the Supplementary Figs. 7-9.

Cell cultures and treatments. HepG2 cells (ATCC) were grown in DMEM containing $5 \mathrm{mM}$ glucose, $10 \%$ calf serum, 100 units $/ \mathrm{ml}$ penicillin, and $100 \mu \mathrm{g} / \mathrm{ml}$ streptomycin at $5 \% \mathrm{CO}_{2}$ and $37^{\circ} \mathrm{C}$. Primary hepatocytes were isolated using liver perfusion with type II collagenase (Worthington Biochem, Lakewood, NJ), and were grown in William E Medium (Sigma, St. Louis, MO) supplemented with $2 \% \mathrm{FBS}, 100 \mathrm{units} / \mathrm{ml}$ penicillin, and $100 \mu \mathrm{g} / \mathrm{ml}$ streptomycin.

HepG2 cells were deprived of serum overnight, pretreated with wortmannin $(100 \mathrm{nM})$ or MK2066 $(100 \mathrm{nM})$ for $30 \mathrm{~min}$, and then stimulated with insulin $(50 \mathrm{nM})$ for $2 \mathrm{~h}$. Additionally, HepG2 cells were pretreated with palmitate $(100 \mu \mathrm{M})$ overnight and then stimulated with insulin $(100 \mathrm{nM})$ for $2 \mathrm{~h}$. Cell extracts were prepared for various assays.

In separate cohorts, HepG2 cells were transfected with Snail1 plasmids. Fortyeight hour later, the cells were derived of serum overnight, and were then treated with cycloheximide $(5 \mu \mathrm{g} / \mathrm{ml})$ in the presence of either insulin $(100 \mathrm{nM})$ or PBS (control) for $0-8 \mathrm{~h}$. Cell extracts were immunoblotted with antibodies against Snail1 or a-tubulin. To calculate half-life, Snaill protein was quantified and normalized to a-tubulin levels. Snaill abundance was presented as a ratio to its baseline levels prior to cycloheximide treatment, and was plotted against durations of cycloheximide treatment. In separate experiments, HepG2 cells were transduced with Snaill adenoviral vectors for $24 \mathrm{~h}$, and then stimulated with insulin $(100 \mathrm{nM})$ with or without MG132 $(5 \mu \mathrm{M})$ for $2 \mathrm{~h}$. Cell extracts were immunoprecipitated with antibody against Snail1 and immunoblotted with antibodies against ubiquitin or Snail1.

Primary hepatocytes were transduced with Snaill or GFP adenoviral vectors (1000 viral particles per cell) for $24 \mathrm{~h}$. Hepatocytes were deprived of serum overnight in DMEM supplemented with $5 \mathrm{mM}$ glucose, and then grown in DMEM with $22.5 \mathrm{mM}$ glucose in the presence or absence of insulin $(50 \mathrm{nM})$ for additional $4 \mathrm{~h}$ or $12 \mathrm{~h}$. Cell extracts were prepared for various assays.

Fasn luciferase reporter assays. The rattus Fasn promoter (from -225 to +45 ) was prepared by PCR (forward primer: 5'-AGTGCCTCTCATGTATGCTTAA-3', and reverse primer: $5^{\prime}$-TCCCGCAGTCTCGATACCTTGG-3') and inserted into pGL3 vectors. HepG2 cells were co-transfected with Fasn, or Fasn ( $S S R E)$, luciferase reporter plasmids and the indicated vectors ${ }^{60}$. Luciferase activities were measured $72 \mathrm{~h}$ after transfection using a kit (Progema, Madison, WI), and were normalized to $\beta$-gal levels (internal control).

De novo lipogenesis. Primary hepatocytes were transduced with the indicated adenoviral vectors as described previously ${ }^{61}$, and concomitantly treated with or without TSA $(2 \mu \mathrm{M})$. De novo lipogenesis was assessed and normalized to total protein levels as described previously ${ }^{62}$. To assess insulin stimulation of lipogenesis, hepatocytes were deprived of serum overnight in the presence of $5 \mathrm{mM}$ glucose, and stimulated with $50 \mathrm{nM}$ insulin for $12 \mathrm{~h}$ prior to lipogenesis assays.

Quantitative real time RT-PCR (qPCR). Total RNAs were extracted using TRIzol reagent (Invitrogen life technologies, Carlsbad, CA). The first-strand cDNAs were synthesized using random primers and M-MLV reverse transcriptase (Promega, Madison, WI). qPCR was performed using Absolute QPCR SYBR Mix (Thermo Fisher Scientific, UK) and Mx3000P real time PCR system (Stratagene, LA Jolla, CA). qPCR primers were listed in supplementary table 2 .

Chromatin immunoprecipitation (ChIP). ChIP assays were described previously ${ }^{11}$. Briefly, liver samples were treated with $1 \%$ formaldehyde for $10 \mathrm{~min}$ to crosslink DNA-protein complexes. Genomic DNA was extracted, and sheared to 200-500 bp fragments using a sonicator (Model Q800R, QSONICA). DNA-protein complexes were immunoprecipitated with the indicated antibodies (Supplementary table 1). Crosslink was reversed by heating at $65^{\circ} \mathrm{C}$ for $4 \mathrm{~h}$. DNA was purified and used for PCR or $\mathrm{qPCR}$ analysis. Primers flanking the putative Snaill-binding motifs of the Fasn promoter were listed in supplementary table 2.

Statistical analysis. Differences between two groups were analyzed by two-tailed Student's t test. Longitudinal data (growth curves, GTT and ITT) were further analyzed by ANOVA and Bonferroni posttest using Prism 7. $P<0.05$ was considered statistically significant.

Data availability. All relevant data are available upon request.

Received: 29 December 2017 Accepted: 19 June 2018

Published online: 16 July 2018

\section{References}

1. Allen, A. M. et al. Nonalcoholic fatty liver disease incidence and impact on metabolic burden and death: a 20 year-community study. Hepatology 67, 1726-1736 (2018)

2. Cohen, J. C., Horton, J. D. \& Hobbs, H. H. Human fatty liver disease: old questions and new insights. Science 332, 1519-1523 (2011).

3. Lewis, J. R. \& Mohanty, S. R. Nonalcoholic fatty liver disease: a review and update. Dig. Dis. Sci. 55, 560-578 (2010).

4. Lambert, J. E., Ramos-Roman, M. A., Browning, J. D. \& Parks, E. J. Increased de novo lipogenesis is a distinct characteristic of individuals with nonalcoholic fatty liver disease. Gastroenterology 146, 726-735 (2014).

5. Rui, L. Energy metabolism in the liver. Compr. Physiol. 4, 177-197 (2014).

6. Beaven, S. W. et al. Reciprocal regulation of hepatic and adipose lipogenesis by liver $\mathrm{x}$ receptors in obesity and insulin resistance. Cell. Metab. 18, 106-117 (2013)

7. Moon, Y. A. et al. The Scap/SREBP pathway is essential for developing diabetic fatty liver and carbohydrate-induced hypertriglyceridemia in animals. Cell. Metab. 15, 240-246 (2012).

8. Moran-Salvador, E. et al. Role for PPARgamma in obesity-induced hepatic steatosis as determined by hepatocyte- and macrophage-specific conditional knockouts. FASEB J. 25, 2538-2550 (2011).

9. Wang, Y., Viscarra, J., Kim, S. J. \& Sul, H. S. Transcriptional regulation of hepatic lipogenesis. Nat. Rev. Mol. Cell Biol. 16, 678-689 (2015).

10. Li, S., Brown, M. S. \& Goldstein, J. L. Bifurcation of insulin signaling pathway in rat liver: mTORC1 required for stimulation of lipogenesis, but not inhibition of gluconeogenesis. Proc. Natl Acad. Sci. USA 107, 3441-3446 (2010).

11. Sun, C. et al. Adipose Snaill regulates lipolysis and lipid partitioning by suppressing adipose triacylglycerol lipase expression. Cell Rep. 17, 2015-2027 (2016).

12. Batlle, E. et al. The transcription factor snail is a repressor of E-cadherin gene expression in epithelial tumour cells. Nat. Cell Biol. 2, 84-89 (2000).

13. Lin, Y., Dong, C. \& Zhou, B. P. Epigenetic regulation of EMT: the Snail story. Curr. Pharm. Des. 20, 1698-1705 (2014).

14. Peinado, H., Ballestar, E., Esteller, M. \& Cano, A. Snail mediates E-cadherin repression by the recruitment of the Sin3A/histone deacetylase 1 (HDAC1)/ HDAC2 complex. Mol. Cell. Biol. 24, 306-319 (2004).

15. Herranz, N. et al. Polycomb complex 2 is required for E-cadherin repression by the Snaill transcription factor. Mol. Cell. Biol. 28, 4772-4781 (2008).

16. Dong, C. et al. G9a interacts with Snail and is critical for Snail-mediated Ecadherin repression in human breast cancer. J. Clin. Invest. 122, 1469-1486 (2012).

17. Kim, B. J. et al. Bacterial induction of Snaill contributes to blood-brain barrier disruption. J. Clin. Invest. 125, 2473-2483 (2015).

18. Kojima, T. et al. Transforming growth factor-beta induces epithelial to mesenchymal transition by down-regulation of claudin-1 expression and the fence function in adult rat hepatocytes. Liver Int. 28, 534-545 (2008).

19. Sekiya, S. \& Suzuki, A. Glycogen synthase kinase 3 beta-dependent Snail degradation directs hepatocyte proliferation in normal liver regeneration. Proc. Natl Acad. Sci. USA 108, 11175-11180 (2011).

20. Rowe, R. G. et al. Hepatocyte-derived Snaill propagates liver fibrosis progression. Mol. Cell. Biol. 31, 2392-2403 (2011).

21. Lan, A., Qi, Y. \& Du, J. Akt2 mediates TGF-beta1-induced epithelial to mesenchymal transition by deactivating GSK3beta/snail signaling pathway in renal tubular epithelial cells. Cell. Physiol. Biochem. 34, 368-382 (2014).

22. Zhou, B. P. et al. Dual regulation of Snail by GSK-3beta-mediated phosphorylation in control of epithelial-mesenchymal transition. Nat. Cell. Biol. 6, 931-940 (2004). 
23. Yook, J. I., Li, X. Y., Ota, I., Fearon, E. R. \& Weiss, S. J. Wnt-dependent regulation of the E-cadherin repressor snail. J. Biol. Chem. 280, 11740-11748 (2005).

24. Cross, D. A., Alessi, D. R., Cohen, P., Andjelkovich, M. \& Hemmings, B. A. Inhibition of glycogen synthase kinase- 3 by insulin mediated by protein kinase B. Nature 378, 785-789 (1995).

25. Rowe, R. G. et al. Mesenchymal cells reactivate Snaill expression to drive three-dimensional invasion programs. J. Cell Biol. 184, 399-408 (2009).

26. Schuler, M., Dierich, A., Chambon, P. \& Metzger, D. Efficient temporally controlled targeted somatic mutagenesis in hepatocytes of the mouse. Genesis 39, 167-172 (2004).

27. Bell, P. et al. Evaluation of adeno-associated viral vectors for liver-directed gene transfer in dogs. Hum. Gene. Ther. 22, 985-997 (2011).

28. Yook, J. I. et al. A Wnt-Axin2-GSK3beta cascade regulates Snaill activity in breast cancer cells. Nat. Cell. Biol. 8, 1398-1406 (2006).

29. Kaimori, A. et al. Transforming growth factor-beta1 induces an epithelial-tomesenchymal transition state in mouse hepatocytes in vitro. J. Biol. Chem. 282, 22089-22101 (2007).

30. Abiola, M. et al. Activation of Wnt/beta-catenin signaling increases insulin sensitivity through a reciprocal regulation of Wnt10b and SREBP-1c in skeletal muscle cells. PLoS ONE 4, e8509 (2009).

31. McNairn, A. J. et al. TGFbeta signaling regulates lipogenesis in human sebaceous glands cells. BMC Dermatol. 13, 2 (2013).

32. Dong, C. et al. Interaction with Suv39H1 is critical for Snail-mediated Ecadherin repression in breast cancer. Oncogene. 32, 1351-1362 (2013).

33. Monetti, M. et al. Dissociation of hepatic steatosis and insulin resistance in mice overexpressing DGAT in the liver. Cell Metab. 6, 69-78 (2007).

34. Shi, $H$. et al. TLR4 links innate immunity and fatty acid-induced insulin resistance. J. Clin. Invest. 116, 3015-3025 (2006).

35. Spruss, A. et al. Toll-like receptor 4 is involved in the development of fructoseinduced hepatic steatosis in mice. Hepatology 50, 1094-1104 (2009).

36. Jornayvaz, F. R. \& Shulman, G. I. Diacylglycerol activation of protein kinase Cepsilon and hepatic insulin resistance. Cell. Metab. 15, 574-584 (2012).

37. Pagadala, M., Kasumov, T., McCullough, A. J., Zein, N. N. \& Kirwan, J. P. Role of ceramides in nonalcoholic fatty liver disease. Trends Endocrinol. Metab. 23, 365-371 (2012).

38. Larter, C. Z. \& Yeh, M. M. Animal models of NASH: getting both pathology and metabolic context right. J. Gastroenterol. Hepatol. 23, 1635-1648 (2008).

39. Mendez-Sanchez, N., Arrese, M., Zamora-Valdes, D. \& Uribe, M. Current concepts in the pathogenesis of nonalcoholic fatty liver disease. Liver Int. 27, 423-433 (2007).

40. Iizuka, K., Bruick, R. K., Liang, G., Horton, J. D. \& Uyeda, K. Deficiency of carbohydrate response element-binding protein (ChREBP) reduces lipogenesis as well as glycolysis. Proc. Natl Acad. Sci. USA 101, 7281-7286 (2004).

41. Dentin, R. et al. Liver-specific inhibition of ChREBP improves hepatic steatosis and insulin resistance in ob/ob mice. Diabetes 55, 2159-2170 (2006).

42. Iizuka, K., Miller, B. \& Uyeda, K. Deficiency of carbohydrate-activated transcription factor ChREBP prevents obesity and improves plasma glucose control in leptin-deficient (ob/ob) mice. Am. J. Physiol. Endocrinol. Metab. 291, E358-E364 (2006)

43. Horton, J. D., Goldstein, J. L. \& Brown, M. S. SREBPs: activators of the complete program of cholesterol and fatty acid synthesis in the liver. J. Clin. Invest. 109, 1125-1131 (2002).

44. Gavrilova, O. et al. Liver peroxisome proliferator-activated receptor gamma contributes to hepatic steatosis, triglyceride clearance, and regulation of body fat mass. J. Biol. Chem. 278, 34268-34276 (2003).

45. Matsusue, K. et al. Liver-specific disruption of PPARgamma in leptin-deficient mice improves fatty liver but aggravates diabetic phenotypes. J. Clin. Invest. 111, 737-747 (2003)

46. Lee, Y. J. et al. Nuclear receptor PPARgamma-regulated monoacylglycerol Oacyltransferase 1 (MGAT1) expression is responsible for the lipid accumulation in diet-induced hepatic steatosis. Proc. Natl Acad. Sci. USA 109, 13656-13661 (2012).

47. Matsusue, K. et al. Hepatic steatosis in leptin-deficient mice is promoted by the PPARgamma target gene Fsp27. Cell. Metab. 7, 302-311 (2008).

48. Steneberg, P. et al. Hyperinsulinemia enhances hepatic expression of the fatty acid transporter Cd36 and provokes hepatosteatosis and hepatic insulin resistance. J. Biol. Chem. 290, 19034-19043 (2015).

49. Kersten, S. et al. Peroxisome proliferator-activated receptor alpha mediates the adaptive response to fasting. J. Clin. Invest. 103, 1489-1498 (1999).

50. Montagner, A. et al. Liver PPARalpha is crucial for whole-body fatty acid homeostasis and is protective against NAFLD. Gut 65, 1202-1214 (2016).

51. Sanderson, L. M. et al. Peroxisome proliferator-activated receptor beta/delta (PPARbeta/delta) but not PPARalpha serves as a plasma free fatty acid sensor in liver. Mol. Cell. Biol. 29, 6257-6267 (2009).
52. Wolfrum, C., Asilmaz, E., Luca, E., Friedman, J. M. \& Stoffel, M. Foxa2 regulates lipid metabolism and ketogenesis in the liver during fasting and in diabetes. Nature 432, 1027-1032 (2004).

53. Wolfrum, C. \& Stoffel, M. Coactivation of Foxa2 through Pgc-1beta promotes liver fatty acid oxidation and triglyceride/VLDL secretion. Cell Metab. 3, 99-110 (2006).

54. Jacobi, D. et al. Hepatic Bmall regulates rhythmic mitochondrial dynamics and promotes metabolic fitness. Cell. Metab. 22, 709-720 (2015).

55. Caron S., et al. Farnesoid X receptor inhibits the transcriptional activity of carbohydrate response element binding protein in human hepatocytes. Mol. Cell. Biol. 33, 2202-2211 (2013).

56. Sinal, C. J. et al. Targeted disruption of the nuclear receptor FXR/BAR impairs bile acid and lipid homeostasis. Cell 102, 731-744 (2000).

57. Watanabe, M. et al. Bile acids lower triglyceride levels via a pathway involving FXR, SHP, and SREBP-1c. J. Clin. Invest. 113, 1408-1418 (2004).

58. Feng, D. et al. A circadian rhythm orchestrated by histone deacetylase 3 controls hepatic lipid metabolism. Science 331, 1315-1319 (2011).

59. Bugge, A. et al. Rev-erbalpha and Rev-erbbeta coordinately protect the circadian clock and normal metabolic function. Genes. Dev. 26, 657-667 (2012).

60. Jiang, B. et al. Carboxyl terminus of HSC70-interacting protein (CHIP) downregulates NF-kappaB-inducing kinase (NIK) and suppresses NIK-induced liver injury. J. Biol. Chem. 290, 11704-11714 (2015).

61. Shen, H. et al. Mouse hepatocyte overexpression of NF-kappaB-inducing kinase (NIK) triggers fatal macrophage-dependent liver injury and fibrosis. Hepatology 60, 2065-2076 (2014).

62. Sheng, L., Cho, K. W., Zhou, Y., Shen, H. \& Rui, L. Lipocalin 13 protein protects against hepatic steatosis by both inhibiting lipogenesis and stimulating fatty acid beta-oxidation. J. Biol. Chem. 286, 38128-38135 (2011)

\section{Acknowledgements}

We thank Drs. Zheng Chen, Mark J. Canet, Hong Shen, Gong Cheng, Deqiang Zhang Yin Lei, Xin Tong, and Bishr M. Omary for assistance and discussions. We thank Dr. Stephen J. Weiss (University of Michigan) for providing Snail1 flox/flox mice. This study was supported by grants DK094014, DK114220, and DK115646 (to L.R.) and DK095201 (to Y.S.) from the National Institutes of Health, American Heart Association Postdoctoral Fellowship 14POST20230007 (to Yan Liu), and National Natural Science Foundation of China Grant 81420108006 (to Yong Liu). This work utilized the cores supported by the Michigan Diabetes Research and Training Center (NIH DK20572), the University of Michigan Nathan Shock Center (NIH P30AG013283), and the University of Michigan Gut Peptide Research Center (NIH DK34933).

\section{Author contributions}

Yan Liu, L.J., C.S., and N.I. conducted the experiments, Yan Liu and L.R. designed the experiments and wrote the paper, and Yan Liu, L.J., C.S., N.I., Y.M.S., Yong Liu, and L.R. performed data analysis and edited the paper.

\section{Additional information}

Supplementary Information accompanies this paper at https://doi.org/10.1038/s41467018-05309-y.

Competing interests: The authors declare no competing interests.

Reprints and permission information is available online at http://npg.nature.com/ reprintsandpermissions/

Publisher's note: Springer Nature remains neutral with regard to jurisdictional claims in published maps and institutional affiliations.

Open Access This article is licensed under a Creative Commons Attribution 4.0 International License, which permits use, sharing, adaptation, distribution and reproduction in any medium or format, as long as you give appropriate credit to the original author(s) and the source, provide a link to the Creative Commons license, and indicate if changes were made. The images or other third party material in this article are included in the article's Creative Commons license, unless indicated otherwise in a credit line to the material. If material is not included in the article's Creative Commons license and your intended use is not permitted by statutory regulation or exceeds the permitted use, you will need to obtain permission directly from the copyright holder. To view a copy of this license, visit http://creativecommons.org/ licenses/by/4.0\%

(C) The Author(s) 2018 